\title{
Pulmonary arterial pressure at rest and during exercise in chronic mountain sickness: a meta-analysis
}

\author{
Rodrigo Soria ${ }^{1}$, Matthias Egger ${ }^{2,3}$, Urs Scherrer ${ }^{1,4}$, Nicole Bender ${ }^{2,5,6}$ and \\ Stefano F. Rimoldi ${ }^{1,6}$
}

Affiliations: ${ }^{1}$ Dept of Cardiology and Clinical Research, Inselspital, University of Bern, Bern, Switzerland. ${ }^{2}$ Institute of Social and Preventive Medicine (ISPM), University of Bern, Bern, Switzerland. ${ }^{3}$ Division of Epidemiology and Biostatistics, School of Public Health and Family Medicine, University of Cape Town, Cape Town, South Africa. ${ }^{4}$ Facultad de Ciencias, Departamento de Biología, Universidad de Tarapacá, Arica, Chile. ${ }^{5}$ Institute of Evolutionary Medicine, University of Zurich, Zurich, Switzerland. ${ }^{6}$ These two authors contributed equally to this work.

Correspondence: Stefano F. Rimoldi, Dept of Cardiology and Clinical Research, Inselspital, University of Bern, SH1 3.303, Freiburgstrasse 10, 3010 Bern, Switzerland. E-mail: stefano.rimoldidinsel.ch

@ERSpublications

This meta-analysis shows that in high-altitude dwellers suffering from chronic mountain sickness, pulmonary hypertension, while rare at rest, is frequent during daily activities http://ow.ly/ Mw8730oiZ4z

Cite this article as: Soria R, Egger M, Scherrer U, et al. Pulmonary arterial pressure at rest and during exercise in chronic mountain sickness: a meta-analysis. Eur Respir J 2019; 53: 1802040 [https://doi.org/ 10.1183/13993003.02040-2018].

ABSTRACT Up to $10 \%$ of the more than 140 million high-altitude dwellers worldwide suffer from chronic mountain sickness (CMS). Patients suffering from this debilitating problem often display increased pulmonary arterial pressure (PAP), which may contribute to exercise intolerance and right heart failure. However, there is little information on the usual PAP in these patients.

We systematically reviewed and meta-analysed all data published in English or Spanish until June 2018 on echocardiographic estimations of PAP at rest and during mild exercise in CMS patients.

Nine studies comprising 287 participants fulfilled the inclusion criteria. At rest, the point estimate from meta-analysis of the mean systolic PAP was $27.9 \mathrm{mmHg}$ (95\% CI 26.3-29.6 mmHg). These values are $11 \%$ $(+2.7 \mathrm{mmHg})$ higher than those previously meta-analysed in apparently healthy high-altitude dwellers. During mild exercise $(50 \mathrm{~W})$ the difference in mean systolic PAP between patients and high-altitude dwellers was markedly more accentuated (48.3 versus $36.3 \mathrm{mmHg}$ ) than at rest.

These findings indicate that in patients with CMS PAP is moderately increased at rest, but markedly increased during mild exercise, which will be common with activities of daily living. 


\section{Introduction}

An increase of pulmonary arterial pressure (PAP) is a hallmark of high-altitude exposure and, if pronounced, it may be associated with important morbidity and mortality. Worldwide more than 140 million people are living at high altitude, of whom a substantial number are suffering from chronic mountain sickness (CMS) [1, 2]. For example, among Andean high-altitude dwellers, an estimated 5-10\% are suffering from this debilitating disease characterised by excessive erythrocytosis and arterial hypoxaemia [2]. CMS patients often also display increased PAP that is thought to contribute to exercise intolerance and right heart failure, which is common in these patients [3,4]. There is, however, little information on the extent of the increase of PAP in CMS.

The advent of echocardiography as a reliable tool to noninvasively estimate and compare PAP between groups [5-7] allowed eliminating the restrictions related to the more precise, but invasive and often unavailable, gold standard measurements by right heart catheterisation and permitted investigators to perform studies under field conditions. Since these studies generally comprise relatively few participants, the prevalence of PAP in high-altitude dwellers suffering from CMS remains ill defined at present.

To fill this gap, we systematically reviewed and meta-analysed all data published in English or Spanish on echocardiographic estimations of PAP and measurements of arterial oxygen saturation in high-altitude dwellers $(>2500 \mathrm{~m})$ suffering from CMS. Moreover, since there is evidence that in patients with CMS mild exercise during daily activities worsens pulmonary hypertension and contributes to the symptoms and long-term complications [3, 8], we also analysed echocardiographic studies of PAP and arterial oxygen saturation during mild exercise in patients with CMS and high-altitude dwellers.

\section{Materials and methods}

We conducted a systematic review and meta-analysis of studies reporting echocardiographic estimates of PAP and arterial oxygen saturation in CMS patients at rest and during exercise. Reviewing and reporting were performed according to the recommendations of the Cochrane collaboration [9] and the PRISMA Statement [10], respectively (supplementary table S1).

\section{Data sources and searches}

We searched the MEDLINE and Embase databases up to June 2018, using PubMed and Ovid platforms. We used free-text words and specific thesaurus terms (MeSH in MEDLINE and Emtree in Embase), including "pulmonary artery", "pressure", "altitude" and "altitude sickness". We also examined the bibliographies of relevant articles to identify eligible studies missed by the database searches (supplementary material).

\section{Study selection}

We included articles that reported the mean value and standard deviation (or standard error) of PAP by Doppler echocardiography in patients with CMS, defined as erythrocytosis with haemoglobin concentration $>21 \mathrm{~g} \cdot \mathrm{dL}^{-1}$ in the presence of a normal pulmonary function and no history of working in the mining industry. We excluded small studies reporting data in less than 10 participants, case reports and studies reporting duplicate data. We first checked the abstracts of retrieved articles for eligibility and excluded ineligible studies at this stage. We then examined the full text of potentially eligible articles and, depending on whether they met eligibility criteria or not, included or excluded articles.

\section{Data extraction}

Two reviewers (R.S. and N.B.) extracted data, using a data extraction sheet developed and piloted for this review. The two reviewers extracted the mean and standard deviation (or standard error) of systolic PAP and, if reported, the mean and standard deviation (or standard error) of arterial oxygen saturation. In the five studies that also reported PAP and arterial oxygen saturation during mild exercise $[3,4,8,11,12]$, data for CMS patients and (for comparison) high-altitude dwellers were extracted.

We used the right ventricular-to-atrial pressure gradient as an estimate of systolic PAP. In most included studies, PAP derives from continuous wave Doppler sampling of the tricuspid regurgitation jet, using the simplified Bernoulli equation. In a few studies that reported mean PAP instead of systolic PAP, we used the following formula to calculate systolic PAP: systolic $\mathrm{PAP}=($ mean $\mathrm{PAP}-2) / 0.61$ [13]. If atrial pressure had been added to the pressure gradient, we subtracted these estimates to obtain a comparable set of data for meta-analysis. Where cardiac output $\left(\mathrm{L} \cdot \mathrm{min}^{-1}\right)$ during exercise at $50 \mathrm{~W}$ was not directly reported, we calculated it according to: stoke volume $(\mathrm{mL}) \times$ heart rate (beats $\left.\cdot \mathrm{min}^{-1}\right) / 1000$. Cardiac index $\left(\mathrm{L} \cdot \mathrm{min}^{-1} \cdot \mathrm{m}^{-2}\right)$ was calculated according to: cardiac output/body surface area $\left(\mathrm{m}^{2}\right)$. Pulmonary vascular resistance (PVR (Wood Units)) was calculated using: $\mathrm{PVR}=($ mean $\mathrm{PAP}-\mathrm{PAWP}) /$ cardiac output, where pulmonary arterial wedge pressure (PAWP) was estimated by left atrial pressure. 
We further extracted bibliographic details, the study location and its altitude, the number, sex, age and ethnicity of the study participants, and the number of participants excluded from the analysis. Discrepancies between the two reviewers were resolved by discussion and consultation with the senior authors (M.E., U.S. or S.F.R.).

\section{Methodological and reporting quality}

We assessed methodological and reporting quality of studies using five criteria. 1) Was the recruitment procedure described? 2) Clear description of inclusion and exclusion criteria. 3) Number of participants with missing data for variables of interest. 4) Was the study population representative for the general population? 5) Was the echocardiography performed according to established standards? 6) Were potential sources of bias addressed?

\section{Statistical analysis}

We combined the data on systolic PAP and arterial oxygen saturation using random effects meta-analysis. We converted standard deviation to standard error by dividing the standard deviation by the square root of the number of participants included in the analysis and expressed results as mean values and 95\% confidence intervals. We used univariate meta-regression models to identify factors that may have influenced PAP in people suffering from CMS. We included age, study altitude, arterial oxygen saturation, body mass index and haemoglobin. We assessed heterogeneity between studies using the $I^{2}$ statistic and the Chi-squared test. We used Stata version 11.2 (StataCorp, College Station, TX, USA) for all analyses.

For the simulated distribution, we plotted normal distributions of systolic PAP and oxygen saturation at rest and during exercise for hypothetical populations with and without CMS, based on means and standard deviations of reported data.

\section{Results}

Identification of eligible studies

We identified a total of 267 articles. Figure 1 shows the flow of the selection of studies and the reasons for exclusion.

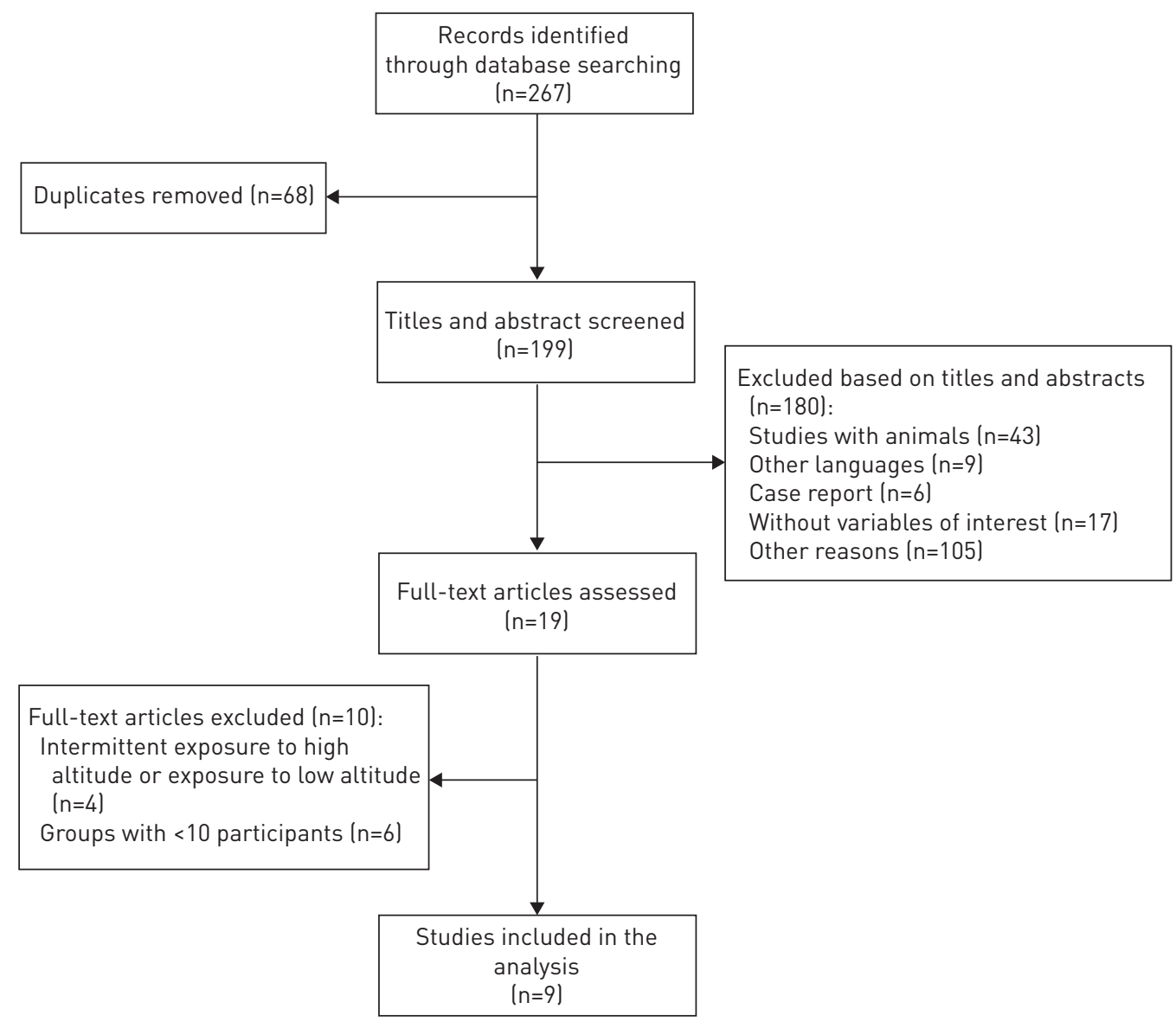

FIGURE 1 Flow of information through the different phases of systematic review. 
Based on titles and abstracts, we excluded 68 duplicates and 180 articles that did not meet inclusion criteria. We examined 19 full-text articles and excluded 10 articles because they did not meet the inclusion criteria (less than 10 participants, high-altitude exposure $<1$ year).

\section{Characteristics of included studies}

Nine studies with a total of 262 participants fulfilled the inclusion criteria [3, 4, 8, 11, 12, 14-17]. The mean age of the participants was 47 years and their number ranged from 58 participants [16] in the largest to 12 participants [15] in the smallest study (table 1). All studies were performed between 3600 and $4350 \mathrm{~m}$ altitude in the Andes. All participants were male and had an indigenous Andean (Aymara or Quechua) background. Five studies, in addition to reporting data at rest, also reported measurements during mild exercise. CMS patients and high-altitude dwellers were matched for age, socioeconomic background and ethnicity.

\section{Methodological and reporting quality}

All studies provided a clear description of the eligibility criteria; however, due to missing or incomplete reporting, it was unclear whether participants were truly representative of the general CMS population. In all studies, echocardiography was performed according to the quality criteria of the European Association of Echocardiography [18]. Some, but not all, studies addressed potential sources of bias (table 2).

Two studies reported a selection bias towards the inclusion of patients with mild to moderate disease $[3,14]$. This may have resulted in an underestimation of the true magnitude of pulmonary hypertension and arterial oxygen desaturation in the present meta-analysis. One study used the same absolute workload for exercise in all participants and did not use a subjective assessment of exercise intensity [4]. Even though the percentage of the maximal heart rate during exercise was similar in CMS patients and controls, the possibility exists that differences in relative workload may have contributed to the large differences of exercise-induced pulmonary hypertension (and pulmonary interstitial fluid accumulation) between the two groups. Finally, in one study, haemoglobin concentration was slightly $<21 \mathrm{~g} \cdot \mathrm{L}^{-1}$ in some patients, because of blood-letting shortly before the time of study [11]. It is unlikely that the slightly lower haemoglobin concentrations altered PAP, since isovolaemic haemodilution has no detectable effect on vascular function in CMS patients [19].

\section{Meta-analysis of PAP and arterial oxygen saturation at rest}

In all studies, experienced echocardiographers performed the PAP measurements. The point estimate from meta-analysis of the mean systolic PAP at rest was $27.96 \mathrm{mmHg}$ (95\% CI 26.28-29.64 mmHg) (figure 2), with the reported mean value ranging from 25.0 to $34.3 \mathrm{mmHg}$. The point estimate of mean arterial oxygen saturation at rest was $84.27 \%$ (95\% CI 82.94-85.61\%) (figure 3), with the reported mean value ranging from $81.0 \%$ to $87.0 \%$. Meta-regression analyses revealed positive relationships between PAP and study altitude $(\mathrm{p}=0.005)$ and haemoglobin $(\mathrm{p}=0.001)$, and a negative correlation between PAP and arterial oxygen saturation $(\mathrm{p}=0.005)$. No significant relationships existed between PAP and age $(\mathrm{p}=0.56)$ or body mass index $(\mathrm{p}=0.98)$.

\begin{tabular}{|c|c|c|c|c|c|c|c|}
\hline $\begin{array}{l}\text { VARGAS (2006) [16] } \\
\text { (young CMS) }\end{array}$ & 30 & $22.3 \pm 4.3$ & $19.5 \pm 0.7$ & & La Paz, Bolivia & 3600 & Aymara \\
\hline $\begin{array}{l}\text { VARGAS (2006) [16] } \\
\text { (old CMS) }\end{array}$ & 28 & $46.7 \pm 7.1$ & $24 \pm 2.3$ & & La Paz, Bolivia & 3600 & Aymara \\
\hline Stuber $(2010)$ [8] & 30 & $47 \pm 13$ & $21.5 \pm 1.7$ & 66 & $\begin{array}{c}\text { La Paz, El Alto, } \\
\text { Bolivia }\end{array}$ & 3600 & Aymara \\
\hline Pratali (2012) [4] & 15 & $54 \pm 9$ & $21.7 \pm 1.3$ & 66 & La Paz, Bolivia & 3600 & Aymara \\
\hline GROEPENHOFF (2012) [17] & 13 & $50 \pm 10.8$ & $24 \pm 3.6$ & & Cerro Pasco, Peru & 4350 & Quechua \\
\hline Pratali (2013) [3] & 46 & $51 \pm 10$ & $21.5 \pm 2$ & 63.3 & La Paz, Bolivia & 3600 & Aymara \\
\hline Dedobbeleer (2015) [15] & 12 & $51 \pm 10$ & $24 \pm 2$ & & Cerro Pasco, Peru & 4350 & Quechua \\
\hline BRENNER (2015) [11] & 35 & $52.4 \pm 11.9$ & $21.6 \pm 2.1$ & 62.5 & La Paz, Bolivia & 3600 & Aymara \\
\hline
\end{tabular}

CMS: chronic mountain sickness. " : all participants were male. 
TABLE 2 Assessment of methodological quality of included studies

\begin{tabular}{|c|c|c|c|c|c|c|}
\hline $\begin{array}{l}\text { First author (year) } \\
\text { [ref.] }\end{array}$ & $\begin{array}{l}\text { Was the } \\
\text { recruitment } \\
\text { procedure } \\
\text { described? }\end{array}$ & $\begin{array}{l}\text { Clear description } \\
\text { of inclusion and } \\
\text { exclusion criteria }\end{array}$ & $\begin{array}{l}\text { Participants with } \\
\text { missing data for } \\
\text { variables of } \\
\text { interest } n(\%)\end{array}$ & $\begin{array}{l}\text { Was the study } \\
\text { population } \\
\text { representative of the } \\
\text { general population? }\end{array}$ & $\begin{array}{l}\text { Was the echocardiography } \\
\text { performed according to } \\
\text { established standards? }\end{array}$ & $\begin{array}{l}\text { Were potential } \\
\text { sources of bias } \\
\text { addressed? }\end{array}$ \\
\hline VARGAS (2006) [16] & No & Yes & Unclear & Unclear & Yes & No \\
\hline MAIGNAN (2009) [14] & No & Yes & 18 (32) & Unclear & Yes & Yes \\
\hline Stuber (2010) [8] & No & Yes & 1 (3.3) & Unclear & Yes & Yes \\
\hline Pratali (2012) [4] & No & Yes & Unclear & Unclear & Yes & Yes \\
\hline GROEPENHOFF (2012) [17] & No & Yes & Unclear & Unclear & Yes & No \\
\hline Pratal (2013) [3] & Yes & Yes & $3(6.5)$ & Unclear & Yes & Yes \\
\hline Dedobbeleer (2015) [15] & No & Yes & Unclear & Unclear & Yes & No \\
\hline BRENNER (2015) [11] & Yes & Yes & Unclear & Unclear & Yes & Unclear \\
\hline ReXhaJ (2016) [12] & Unclear & Yes & $3(13.0)$ & Unclear & Yes & No \\
\hline
\end{tabular}

Meta-analysis of PAP and arterial oxygen saturation during mild exercise (50 W)

Five studies also reported data on systolic PAP and arterial oxygen saturation (figure 4) during mild exercise $(50 \mathrm{~W})$ in CMS patients $(\mathrm{n}=142)$ and high-altitude dwellers $(\mathrm{n}=125)$. The exercise-induced increase of PAP was almost 2-fold larger in CMS patients than in high-altitude dwellers (22.0 versus $13.0 \mathrm{mmHg} ; \mathrm{p}=0.001)$. The point estimate of systolic PAP during mild exercise in CMS patients was significantly $(\mathrm{p}=0.001)$ higher $(48.26 \mathrm{mmHg}(95 \% \mathrm{CI} 44.76-51.76 \mathrm{mmHg}))$ than in high-altitude dwellers (36.26 mmHg (95\% CI 32.99-39.53 mmHg)). Average systolic PAP during mild exercise ranged from 45.0 to $56.4 \mathrm{mmHg}$ in CMS patients and from 33.0 to $39.8 \mathrm{mmHg}$ in high-altitude dwellers. The point estimate of arterial oxygen saturation during exercise was considerably lower $(\mathrm{p}=0.0004)$ in CMS patients $(82.14 \%$ $(95 \%$ CI $80.57-83.72 \%)$ ) than in controls $(89.40 \%$ (95\% CI $88.54-90.26 \%)$ ) and its mean value ranged from $79.0 \%$ to $84.9 \%$ in the patients and from $87.7 \%$ to $90.3 \%$ in the controls.

CO during mild exercise was comparable in CMS patients and controls $\left(9.4 \pm 1.1\right.$ versus $9.2 \pm 0.9 \mathrm{~L} \cdot \mathrm{min}^{-1}$; $\mathrm{p}=0.80)$, whereas left atrial pressure was slightly, albeit significantly higher in the patients $(10.1 \pm 0.7$ versus $9.2 \pm 0.3 \mathrm{mmHg} ; \mathrm{p}=0.0457)$. Calculated PVR at $50 \mathrm{~W}$ tended to be higher in the patients $(2.7 \pm 0.3$ versus 2.2 $\pm 0.6 \mathrm{mmHg} \cdot \mathrm{min} \cdot \mathrm{L}^{-1} ; \mathrm{p}=0.090$ ), a tendency which disappeared after correction for the increased haematocrit according to VANDERPOOL and NAeIJE [20].

In all meta-analyses the heterogeneity was between $60 \%$ and $85 \%$, which in all cases was significant ( $\mathrm{p}$-values between 0.04 and 0.0001 ).

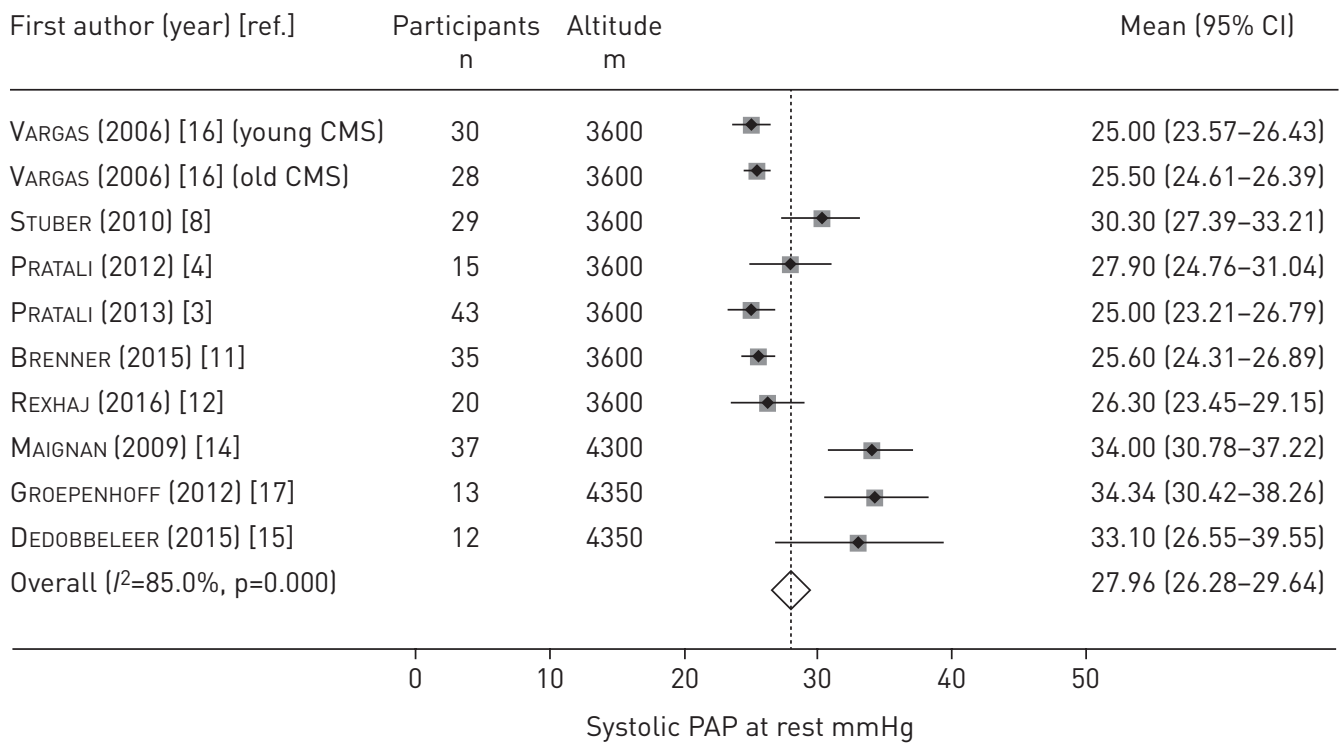

FIGURE 2 Meta-analysis of mean systolic pulmonary arterial pressure (PAP) at rest in high-altitude dwellers suffering from chronic mountain sickness (CMS). Weights are from random effects analysis. 


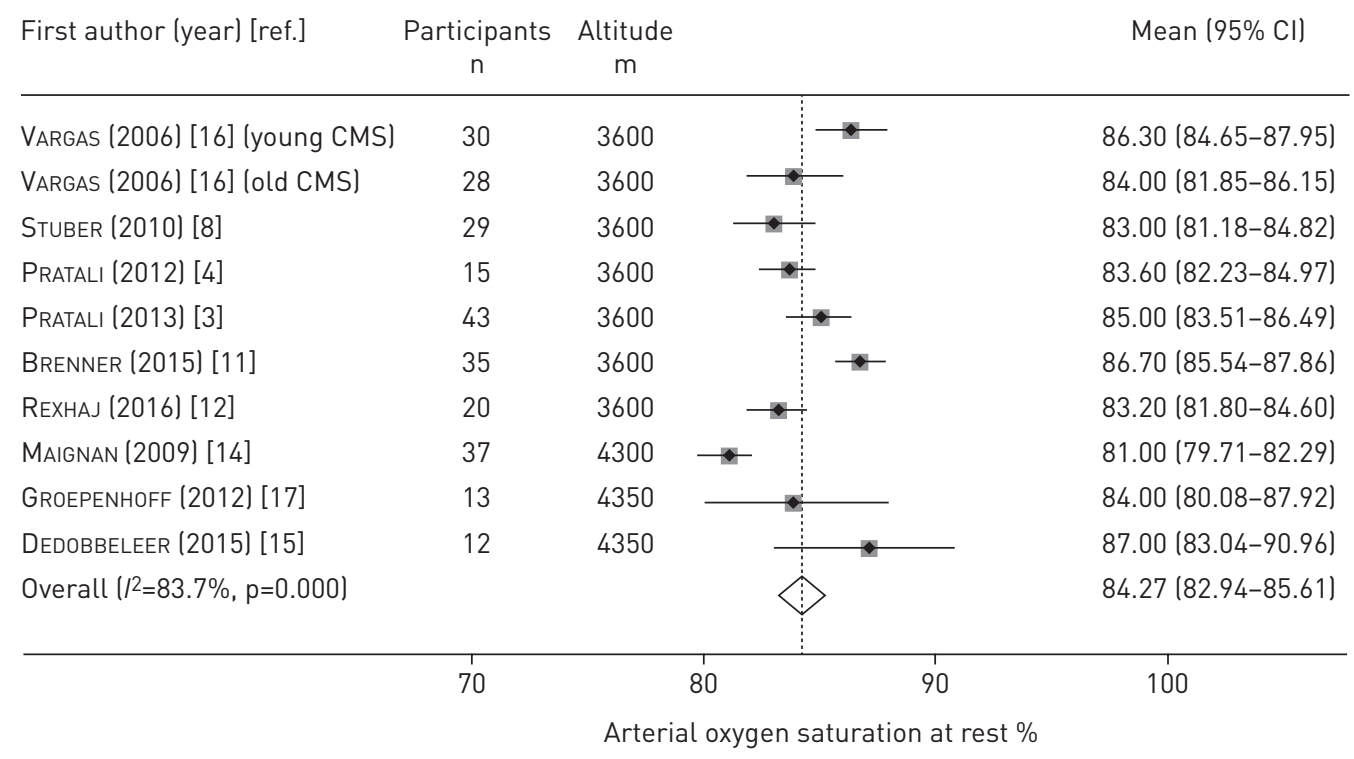

FIGURE 3 Meta-analysis of mean arterial oxygen saturation at rest in high-altitude dwellers suffering from chronic mountain sickness (CMS). Weights are from random effects analysis.

a)

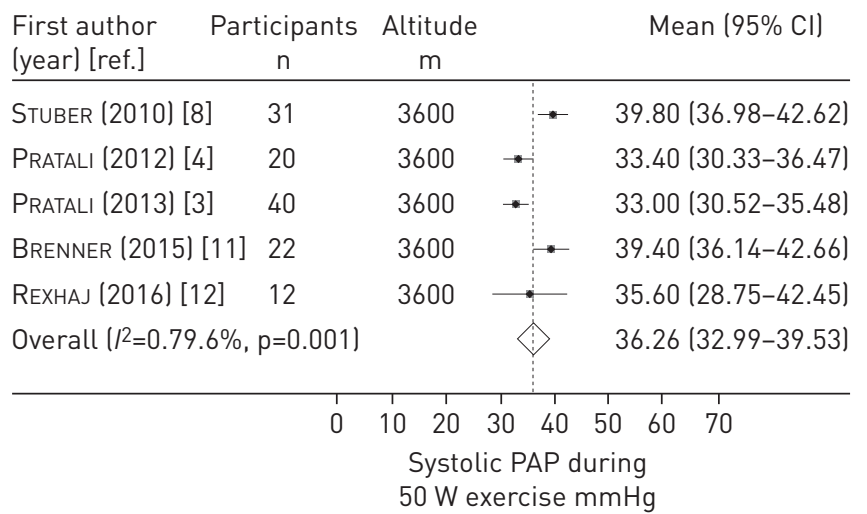

c)

\begin{tabular}{|c|c|c|c|}
\hline $\begin{array}{l}\text { First author } \\
\text { (year) [ref.] }\end{array}$ & $\begin{array}{l}\text { articipants } \\
\text { n }\end{array}$ & $\begin{array}{c}\text { Altitude } \\
\mathrm{m}\end{array}$ & Mean $(95 \% \mathrm{CI})$ \\
\hline STUBeR (2010) [8] & 31 & 3600 & $90.00(89.30-90.70)$ \\
\hline Pratali (2012) [4] & 20 & 3600 & $90.30(88.90-91.70)$ \\
\hline Pratali (2013) [3] & 40 & 3600 & $90.00(89.58-90.42)$ \\
\hline BRENNER (2015) [11] & 1] 22 & 3600 & $88.20(87.36-89.04)$ \\
\hline REXHAJ (2016) [12] & 12 & $3600 \longrightarrow$ & $87.70(85.61-89.79)$ \\
\hline \multicolumn{2}{|c|}{ Overall $\left({ }^{2}=0.79 .2 \%, p=0.001\right)$} & & $89.40(88.54-90.26)$ \\
\hline & 80 & & 100 \\
\hline
\end{tabular}

b)

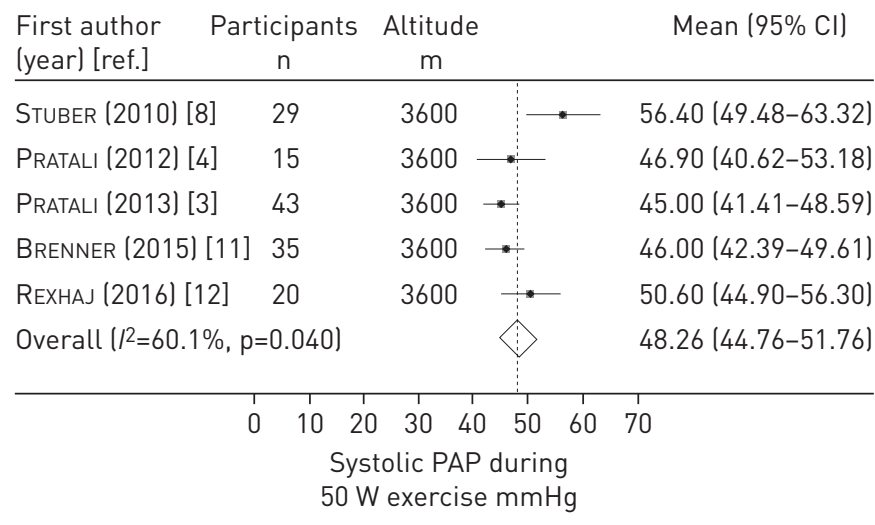

d)

\begin{tabular}{|c|c|c|c|}
\hline $\begin{array}{l}\text { First author } \\
\text { (year) [ref.] }\end{array}$ & $\begin{array}{l}\text { ticipants } \\
n\end{array}$ & $\begin{array}{l}\text { Altitude } \\
\text { m }\end{array}$ & Mean $(95 \% \mathrm{Cl})$ \\
\hline StUBer (2010) [8] & 29 & $3600 \longrightarrow$ & 79.00 (76.09-81.91) \\
\hline Pratali (2012) [4] & 15 & 3600 & $80.30(77.36-83.24)$ \\
\hline Pratali (2013) [3] & 43 & 3600 & $83.00(82.55-83.45)$ \\
\hline BRENNER (2015) [11] & 35 & 3600 & $-84.90(83.74-86.06)$ \\
\hline REXHAJ (2016) [12] & 20 & 3600 & 81.30 (79.92-82.88) \\
\hline \multicolumn{2}{|c|}{ Overall $\left({ }^{2}=84.2 \%, p=0.000\right)$} & & $82.14(80.57-83.72)$ \\
\hline & 70 & 80 & 90 \\
\hline
\end{tabular}

FIGURE 4 Meta-analysis of $a, b)$ mean systolic pulmonary arterial pressure (PAP) and c, d) mean arterial oxygen saturation during mild exercise $(50 \mathrm{~W})$ in $a, c)$ high-altitude dwellers (controls) and b, d) chronic mountain sickness patients. Weights are from random effects analysis. 
FIGURE 5 Predicted distribution of systolic pulmonary arterial pressure (PAP) in high-altitude dwellers (controls) and chronic mountain sickness (CMS) patients at rest and during mild exercise.

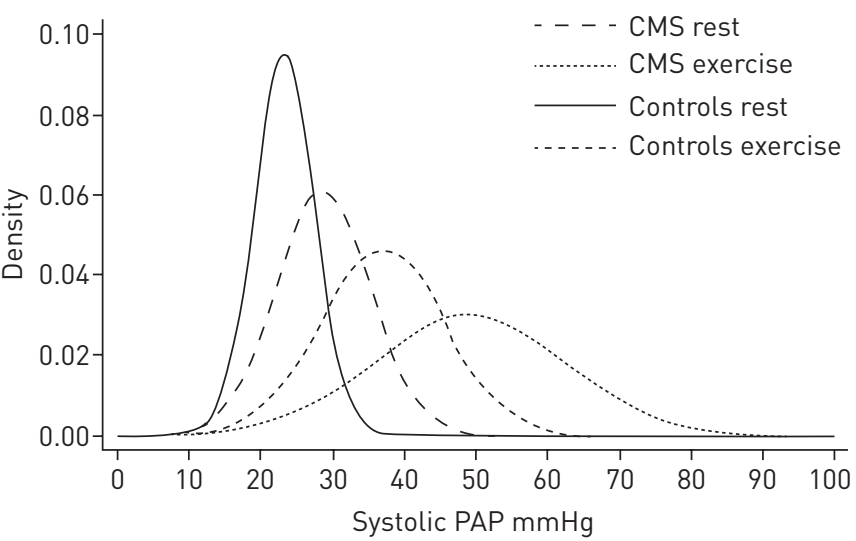

Simulated distribution of PAP and arterial oxygen saturation in CMS patients and high-altitude dwellers

Figures 5 and 6 show simulated distribution curves of PAP and arterial oxygen saturation in CMS patients and high-altitude dwellers at rest and during mild exercise. Curves are shifted towards higher (PAP), respectively lower (arterial oxygen saturation), values in the patients.

\section{Discussion}

CMS represents a major health problem among the more than 140 million people living at high altitude. In the Andes, $5-10 \%$ of high-altitude dwellers suffer from this debilitating disease, which is often associated with increased PAP that is thought to lead to substantial morbidity and mortality $[1,2]$. However, the extent of this increase remains poorly defined. To provide such information, we performed a meta-analysis on echocardiographic estimations of PAP and arterial oxygen saturation in 287 high-altitude dwellers suffering from CMS. Since PAP measurements at rest underestimate the values observed during daily activity [8], we also searched for measurements of PAP during mild exercise in the meta-analysed studies [21]. The meta-analysis revealed mean systolic PAP and mean arterial oxygen saturation are roughly $11 \%$ higher and $6 \%$ lower, respectively, than those meta-analysed previously in high-altitude dwellers living at similar altitude. Mild exercise strikingly accentuates the differences of PAP and arterial oxygen desaturation between the two groups. Taken together, these findings suggest that in CMS patients the PAP increase appears sufficiently severe to cause symptoms and long-term sequels.

The present data represent by far the largest dataset on PAP and arterial oxygen saturation in patients suffering from CMS. Echocardiography is the standard technique to assess PAP in high-altitude populations, since for ethical and logistic reasons invasive measurements are not feasible in population-based studies [21]. Echocardiographic estimations of PAP have been validated against invasive measurements at high altitude [5] with good agreement between invasive and noninvasive measurements $[6,22]$. Moreover, agreement between echocardiographic and invasive measures of pulmonary pressures during exercise is good among patients with a high-quality tricuspid regurgitation Doppler signal [23]. Finally, the accuracy of echocardiographic estimations of PAP may depend on the experience of the echocardiographer. It is important to note that experienced investigators who had published extensively in the field performed the estimations of PAP in all the

FIGURE 6 Predicted distribution of arterial oxygen saturation in high-altitude dwellers (controls) and chronic mountain sickness (CMS) patients at rest and during mild exercise.

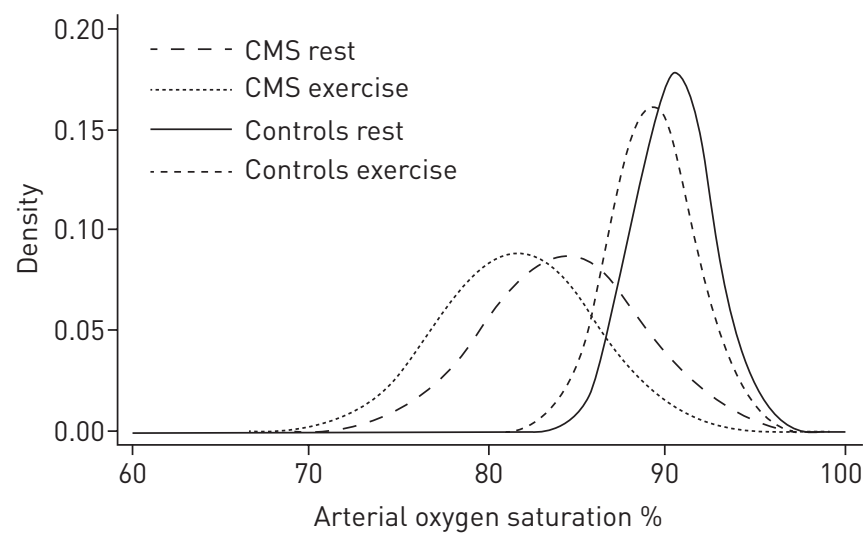


studies meta-analysed [13, 24-26]. Taking the current definitions of pulmonary hypertension as mean PAP $>25 \mathrm{mmHg}$ (European Society of Cardiology/European Respiratory Society) [27] or $>30 \mathrm{mmHg}$ (high-altitude consensus) [2], the findings of our meta-analysis (systolic PAP of $27.9 \mathrm{mmHg}=\mathrm{mean}$ PAP of $19 \mathrm{mmHg}$ ) indicate that pulmonary hypertension at rest is rare in CMS patients living at high altitude $(3600-4350 \mathrm{~m})$.

The high-altitude consensus [2] states that this limit holds true in the absence of excessive erythrocytosis, implying that an increased haematocrit may be a cause of falsely diagnosed pulmonary hypertension [28]. This effect, which could contribute to differences in PAP between high-altitude populations showing different erythropoietic responses to ambient hypoxia, has, however, never been systematically quantified. Along the same lines, the effects of blood-letting as treatment of increased PAP in CMS are controversial [29-33] and need to be re-examined in controlled prospective studies.

An important strength of the present study is that we also meta-analysed PAP during exercise. There is evidence that PAP measurements at rest may greatly underestimate PAP values during daily activity in CMS patients. In turn, this might underestimate the potential consequences of increased PAP for long-term morbidity and mortality in this population [8]. To provide information on this important issue, we included in our meta-analysis studies assessing PAP during mild exercise $(50 \mathrm{~W})$, which will be associated with many activities of daily living. Of note, all exercise studies were performed in the semirecumbent position, a procedure suitable to obtain reliable and reproducible tricuspid regurgitation envelopes during exercise [7].

During mild exercise, the difference in mean systolic PAP between CMS patients and high-altitude dwellers was markedly greater (48.3 versus $36.3 \mathrm{mmHg}$ ) than that meta-analysed previously at rest $(28.0$ versus $25.0 \mathrm{mmHg}$ in CMS versus controls) [21]. Indeed, in CMS patients mean PAP during mild exercise at $50 \mathrm{~W}(36.3 \mathrm{mmHg}(95 \% \mathrm{CI} 33.0-39.5) \mathrm{mmHg})$ ) is above the recently suggested definition of exercise-induced pulmonary hypertension (mean PAP $>30 \mathrm{mmHg}$ ) [34], whereas in high-altitude dwellers mean PAP remains below this suggested cut-off value $(27.2 \mathrm{mmHg}(95 \%$ CI $25.2-29.3 \mathrm{mmHg})$ ). There is consensus emerging to define exercise-induced pulmonary hypertension by mean $\mathrm{PAP}>30 \mathrm{mmHg}$ at cardiac output $<10 \mathrm{~L} \cdot \mathrm{min}^{-1}$ and total pulmonary resistance $>3$ Wood Units, in the absence of pulmonary hypertension at rest [34]. The present meta-analysis demonstrates that CMS patients fulfil two of these three criteria already at mild exercise. It is likely that many of them will fulfil all three criteria at maximal exercise. In line with this speculation, in the study of Groepenhoff et al. [17], we estimated PVR 3.7 Wood Units in CMS patients at maximal exercise.

Of note, in disease states predisposing to pulmonary hypertension, exercise-induced pulmonary hypertension is a well-established cause of decreased exercise capacity, precedes the development of manifest pulmonary hypertension at rest in a proportion of patients and is associated with decreased life expectancy [34]. Several mechanisms may increase PAP in CMS. Pulmonary resistive vessels are less distensible in CMS patients than in healthy highlanders, probably because of vascular remodelling $[8,17]$, which is also detectable in the systemic circulation [19]. Moreover, exaggerated sympathetic activation [35] in conjunction with increased oxidative/nitrosative stress and decreased nitric oxide bioavailability [36, 37] may also facilitate pulmonary vasoconstriction. Finally, exercise-induced arterial oxygen desaturation was considerably more severe in the patients than in the control subjects ( $82.1 \%$ versus $89.4 \%)$.

Collectively, these data strengthen the concept that measurements at rest markedly underestimate pulmonary hypertension and arterial oxygen desaturation during daytime activity in patients with CMS. Interestingly, recent data show that sleep disordered breathing and nocturnal hypoxaemia are more severe in CMS patients than in control subjects [12] and associated with pulmonary vascular dysfunction. It appears therefore possible that daytime measurements of PAP at rest also underestimate differences in PAP between CMS and high-altitude dwellers during sleep. In line with this speculation, invasive measurements of PAP in patients with obstructive sleep apnoea showed a marked progressive increase of PAP during the night [38].

All studies meta-analysed here were performed in Andean high-altitude dwellers. This may be related, at least in part, to the fact that the prevalence of CMS appears to be considerably higher in Andean than in Tibetan or African high-altitude dwellers [39]. Genetic studies provide evidence for differences in the evolutionary adaptation to high altitude between Andean, Tibetan and Ethiopian high-altitude populations [40]. These differences may have resulted in different regulation of the pulmonary circulation and may contribute to differences in PAP between high-altitude populations. It would be important to assess PAP in CMS patients of other than Andean origin.

We used meta-regression models to identify factors that may have influenced PAP in CMS patients. We found that significant positive relationships existed between PAP and study altitude and haemoglobin 
concentration. Moreover, a significant negative relationship existed between PAP and arterial oxygen saturation. The significant relationship between study altitude and PAP (and arterial oxygen saturation) also indicates that differences in study altitude explain, at least in part, the heterogeneity of the studies meta-analysed. Other reasons for the heterogeneity might be differences in CMS severity between studies or other unreported differences between study populations.

Although the present data represent by far the largest dataset on PAP and arterial oxygen saturation at rest and during mild exercise in patients with CMS and high-altitude dwellers, the number of subjects remains relatively small and is limited to Andeans. Additional studies assessing PAP and arterial oxygen saturation at rest and during mild exercise in CMS patients living in the Andes and, importantly, in other high-altitude regions of the world are urgently needed. Finally, one should keep in mind that echocardiographic measurements of PAP, while highly accurate for population studies, are inappropriate for diagnostic decisions in individuals, because of their lack of precision.

To conclude, this is the first systematic review and meta-analysis of studies reporting echocardiographic estimates of PAP and measurements of arterial oxygen saturation in high-altitude dwellers suffering from CMS. The data indicate that in CMS patients, mean systolic PAP at rest is roughly $3 \mathrm{mmHg}$ higher and arterial oxygen saturation $6 \%$ lower than the values previously meta-analysed in high-altitude dwellers [21], but PAP at rest does not fulfil the current criteria for pulmonary hypertension. Importantly, mild exercise expected to be frequently associated with daily activity markedly accentuates the difference in PAP between patients and controls. Exercise-induced pulmonary hypertension may cause symptoms and long-term sequelae in high-altitude dwellers.

The exaggerated increase of PAP during exercise induces interstitial fluid accumulation in the lung [4] and may represent a cause of exertional dyspnoea frequently encountered in CMS patients. Moreover, exercise-induced pulmonary hypertension, however measured, has been shown to be of diagnostic and/or prognostic relevance in mitral valve disease [41], aortic stenosis [42], heart failure [43], systemic sclerosis [44-46], chronic obstructive pulmonary disease [47] and symptomatic patients after pulmonary endarterectomy [48]. Prospective studies are urgently needed examining whether similar long-term sequelae are present CMS patients.

Conflict of interest: None declared.

Support statement: The authors acknowledge funding from Bundesbehörden der Schweizerischen Eidgenossenschaft (Federal Authorities of the Swiss Confederation). R. Soria was the recipient of a Swiss Federal-Excellence Scholarship for foreign scholars.

\section{References}

1 Antezana AM, Antezana G, Aparicio O, et al. Pulmonary hypertension in high-altitude chronic hypoxia: response to nifedipine. Eur Respir J 1998; 12: 1181-1185.

2 Leon-Velarde F, Maggiorini M, Reeves JT, et al. Consensus statement on chronic and subacute high altitude diseases. High Alt Med Biol 2005; 6: 147-157.

3 Pratali L, Allemann Y, Rimoldi SF, et al. RV contractility and exercise-induced pulmonary hypertension in chronic mountain sickness: a stress echocardiographic and tissue Doppler imaging study. JACC Cardiovasc Imaging 2013; 6: 1287-1297.

4 Pratali L, Rimoldi SF, Rexhaj E, et al. Exercise induces rapid interstitial lung water accumulation in patients with chronic mountain sickness. Chest 2012; 141: 953-958.

5 Allemann Y, Sartori C, Lepori M, et al. Echocardiographic and invasive measurements of pulmonary artery pressure correlate closely at high altitude. Am J Physiol Heart Circ Physiol 2000; 279: H2013-H2016.

6 Claessen G, La Gerche A, Voigt JU, et al. Accuracy of echocardiography to evaluate pulmonary vascular and RV function during exercise. JACC Cardiovasc Imaging 2016; 9: 532-543.

7 D'Alto M, Romeo E, Argiento P, et al. Accuracy and precision of echocardiography versus right heart catheterization for the assessment of pulmonary hypertension. Int J Cardiol 2013; 168: 4058-4062.

8 Stuber T, Sartori C, Schwab M, et al. Exaggerated pulmonary hypertension during mild exercise in chronic mountain sickness. Chest 2010; 137: 388-392.

9 Higgins JP, Thompson SG. Quantifying heterogeneity in a meta-analysis. Stat Med 2002; 21: $1539-1558$.

10 Liberati A, Altman DG, Tetzlaff J, et al. The PRISMA statement for reporting systematic reviews and metaanalyses of studies that evaluate health care interventions: explanation and elaboration. PLoS Med 2009; 6: e1000100.

11 Brenner R, Pratali L, Rimoldi SF, et al. Exaggerated pulmonary hypertension and right ventricular dysfunction in high-altitude dwellers with patent foramen ovale. Chest 2015; 147: 1072-1079.

12 Rexhaj E, Rimoldi SF, Pratali L, et al. Sleep-disordered breathing and vascular function in patients with chronic mountain sickness and healthy high-altitude dwellers. Chest 2016; 149: 991-998.

13 Faoro V, Huez S, Vanderpool R, et al. Pulmonary circulation and gas exchange at exercise in Sherpas at high altitude. J Appl Physiol 2014; 116: 919-926.

14 Maignan M, Rivera-Ch M, Privat C, et al. Pulmonary pressure and cardiac function in chronic mountain sickness patients. Chest 2009; 135: 499-504.

15 Dedobbeleer C, Hadefi A, Pichon A, et al. Left ventricular adaptation to high altitude: speckle tracking echocardiography in lowlanders, healthy highlanders and highlanders with chronic mountain sickness. Int $J$ Cardiovasc Imaging 2015; 31: 743-752. 
16 Vargas E, Spielvogel H. Chronic mountain sickness, optimal hemoglobin, and heart disease. High Alt Med Biol 2006; 7: 138-149.

17 Groepenhoff H, Overbeek MJ, Mule M, et al. Exercise pathophysiology in patients with chronic mountain sickness exercise in chronic mountain sickness. Chest 2012; 142: 877-884.

18 Galderisi M, Henein MY, D’Hooge J, et al. Recommendations of the European Association of Echocardiography: how to use echo-Doppler in clinical trials: different modalities for different purposes. Eur J Echocardiogr 2011; 12: 339-353.

19 Rimoldi SF, Rexhaj E, Pratali L, et al. Systemic vascular dysfunction in patients with chronic mountain sickness. Chest 2012; 141: 139-146.

20 Vanderpool RR, Naeije R. Hematocrit-corrected pulmonary vascular resistance. Am J Respir Crit Care Med 2018; 198: 305-309.

21 Soria R, Egger M, Scherrer U, et al. Pulmonary artery pressure and arterial oxygen saturation in people living at high or low altitude: systematic review and meta-analysis. J Appl Physiol 2016; 121: 1151-1159.

22 Penaloza D, Arias-Stella J. The heart and pulmonary circulation at high altitudes: healthy highlanders and chronic mountain sickness. Circulation 2007; 115: 1132-1146.

23 van Riel AC, Opotowsky AR, Santos M, et al. Accuracy of echocardiography to estimate pulmonary artery pressures with exercise: a simultaneous invasive-noninvasive comparison. Circ Cardiovasc Imaging 2017; 10: e005711.

24 Allemann Y, Stuber T, de Marchi SF, et al. Pulmonary artery pressure and cardiac function in children and adolescents after rapid ascent to 3450 m. Am J Physiol Heart Circ Physiol 2012; 302: H2646-H2653.

25 Bruno RM, Cogo A, Ghiadoni L, et al. Cardiovascular function in healthy Himalayan high-altitude dwellers. Atherosclerosis 2014; 236: 47-53.

26 Richalet JP, Rivera-Ch M, Maignan M, et al. Acetazolamide for Monge's disease: efficiency and tolerance of 6-month treatment. Am J Respir Crit Care Med 2008; 177: 1370-1376.

27 Galiè N, Humbert M, Vachiery JL, et al. 2015 ESC/ERS Guidelines for the diagnosis and treatment of pulmonary hypertension: The Joint Task Force for the Diagnosis and Treatment of Pulmonary Hypertension of the European Society of Cardiology (ESC) and the European Respiratory Society (ERS): Endorsed by: Association for European Paediatric and Congenital Cardiology (AEPC), International Society for Heart and Lung Transplantation (ISHLT). Eur Respir J 2015; 46: 903-975.

28 Hoffman JI. Pulmonary vascular resistance and viscosity: the forgotten factor. Pediatr Cardiol 2011; 32: 557-561.

29 Manier G, Guenard H, Castaing Y, et al. Pulmonary gas exchange in Andean natives with excessive polycythemia - effect of hemodilution. J Appl Physiol 1988; 65: 2107-2117.

30 Rivera-Ch M, Leon-Velarde F, Huicho L. Treatment of chronic mountain sickness: critical reappraisal of an old problem. Respir Physiol Neurobiol 2007; 158: 251-265.

31 Smith TG, Balanos GM, Croft QP, et al. The increase in pulmonary arterial pressure caused by hypoxia depends on iron status. J Physiol 2008; 586: 5999-6005.

32 Smith TG, Talbot NP, Privat C, et al. Effects of iron supplementation and depletion on hypoxic pulmonary hypertension: two randomized controlled trials. JAMA 2009; 302: 1444-1450.

33 Naeije R, Vanderpool R. Pulmonary hypertension and chronic mountain sickness. High Alt Med Biol 2013; 14: $117-125$.

34 Naeije R, Saggar R, Badesch D, et al. Exercise-induced pulmonary hypertension: translating pathophysiologica concepts into clinical practice. Chest 2018; 154: 10-15.

35 Lundby C, Calbet J, van Hall G, et al. Sustained sympathetic activity in altitude acclimatizing lowlanders and high-altitude natives. Scand J Med Sci Sports 2018; 28: 854-861.

36 Bailey DM, Rimoldi SF, Rexhaj E, et al. Oxidative-nitrosative stress and systemic vascular function in highlanders with and without exaggerated hypoxemia. Chest 2013; 143: 444-451.

37 Bailey DM, Brugniaux JV, Filipponi T, et al. Exaggerated systemic oxidative-inflammatory-nitrosative stress in chronic mountain sickness is associated with cognitive decline and depression. J Physiol 2019; 597: 611-629.

38 Sforza E, Laks L, Grunstein RR, et al. Time course of pulmonary artery pressure during sleep in sleep apnoea syndrome: role of recurrent apnoeas. Eur Respir J 1998; 11: 440-446.

39 Moore LG. Measuring high-altitude adaptation. J Appl Physiol 2017; 123: 1371-1385.

40 Bigham AW, Wilson MJ, Julian CG, et al. Andean and Tibetan patterns of adaptation to high altitude. Am J Hum Biol 2013; 25: 190-197.

41 Magne J, Lancellotti P, Pierard LA. Exercise pulmonary hypertension in asymptomatic degenerative mitral regurgitation. Circulation 2010; 122: 33-41.

42 Lancellotti P, Magne J, Donal E, et al. Determinants and prognostic significance of exercise pulmonary hypertension in asymptomatic severe aortic stenosis. Circulation 2012; 126: 851-859.

43 Lewis GD, Murphy RM, Shah RV, et al. Pulmonary vascular response patterns during exercise in left ventricular systolic dysfunction predict exercise capacity and outcomes. Circ Heart Fail 2011; 4: 276-285.

44 Condliffe R, Kiely DG, Peacock AJ, et al. Connective tissue disease-associated pulmonary arterial hypertension in the modern treatment era. Am J Respir Crit Care Med 2009; 179: 151-157.

45 Saggar R, Khanna D, Furst DE, et al. Exercise-induced pulmonary hypertension associated with systemic sclerosis: four distinct entities. Arthritis Rheum 2010; 62: 3741-3750.

46 Kovacs G, Maier R, Aberer E, et al. Borderline pulmonary arterial pressure is associated with decreased exercise capacity in scleroderma. Am J Respir Crit Care Med 2009; 180: 881-886.

47 Kessler R, Faller M, Weitzenblum E, et al. "Natural history" of pulmonary hypertension in a series of 131 patients with chronic obstructive lung disease. Am J Respir Crit Care Med 2001; 164: 219-224.

48 Claessen G, La Gerche A, Dymarkowski S, et al. Pulmonary vascular and right ventricular reserve in patients with normalized resting hemodynamics after pulmonary endarterectomy. J Am Heart Assoc 2015; 4: e001602. 